\title{
Incomplete Development of the Brain-Pituitary-Gonadal Axis May Underlie the Delay in the Initiation of Precocious Maturation in Male Sockeye Salmon
}

\author{
Masafumi Amano, ${ }^{* 1, \dagger}$ Naoto Okumoto, ${ }^{* 1}$ and Katsumi Aida*2 \\ ${ }^{* 1}$ Nikko Branch, National Research Institute of Aquaculture, Nikko, Tochigi 321-16, Japan \\ ${ }^{* 2}$ Department of Aquatic Bioscience, Graduate School of Agricultural and Life Sciences, \\ The University of Tokyo, Bunkyo, Tokyo 113, Japan
}

(Received November 27, 1996)

\begin{abstract}
Precocious males first appear in the second year in sockeye salmon, whereas in masu salmon they appear in the first year. In underyearling male masu salmon, precocious maturation is accelerated under short photoperiod with an increase in salmon gonadotropin-releasing hormone (sGnRH) and pituitary gonadotropin subunit (GTH I $\beta$ and GTH II $\beta$ ) contents, suggesting that the brain-pituitary-gonadal axis is already completed. In this study, the development of the brain-pituitary-gonadal axis in underyearling male sockeye salmon was investigated by manipulating photoperiod in order to clarify the relationship between its development and initiation of precocious maturation. Fish were divided into short (8L-16D) and long photoperiodic (16L-8D) groups in June and were reared for 4 months until October. sGnRH contents in the brain and pituitary, and GTH I $\beta$ and GTH II $\beta$ contents in the pituitary were measured. sGnRH contents in the hypothalamus and the pituitary, and GTH I $\beta$ contents in the pituitary increased under short photoperiod, although gonadal maturation was not induced under either photoperiod. However, pituitary GTH II $\beta$ contents did not increase in either photoperiodic group. These results suggest that in contrast to masu salmon, the brain-pituitary-gonadal axis is not completed in underyearling male sockeye salmon. This species-specific difference in the development of the brain-pituitary-gonadal axis may underlie differences in the initiation of precocious maturation.
\end{abstract}

Key words: precocious, salmon GnRH, GTH, sockeye salmon

It is well known that precocious maturation occurs in male salmonid fishes including Atlantic salmon Salmo salar, ${ }^{1,2)}$ amago salmon Oncorhynchus rhodurus, ${ }^{3)}$ masu salmon Oncorhynchus masou, ${ }^{4-6)}$ and sockeye salmon Oncorhynchus nerka (Amano et al., unpublished data). However, the age at which fish mature precociously differs according to species. For example, most male masu salmon mature precociously in the first autumn, while precocious males first appear in the second summer in sockeye salmon landlocked in Japanese lakes. Although the cause of this species-specific difference in the initiation of precocious maturation is of much interest, fundamental mechanisms have not yet been elucidated.

Gonadal maturation in teleost fishes is regulated by the brain-pituitary-gonadal axis; gonadotropin-releasing hormone (GnRH) which is synthesized in the brain stimulates the synthesis and release of gonadotropin (GTH) in the pituitary, and the thus-released GTH stimulates steroid hormone secretion from the gonads. ${ }^{7}$ Thus, there is a possibility that the periodic difference in the appearance of precocious maturation between masu salmon and sockeye salmon is due to differences in the development of the brain-pituitary-gonadal axis.

We have previously shown that the brain-pituitarygonadal axis is already completed in underyearling male masu salmon; salmon GnRH (sGnRH) mRNA levels in the brain and GTH II contents in the pituitary increased with the advancement of testicular maturation controlled experimentally by manipulating photoperiod. ${ }^{8,9}$

In the present study, we manipulated photoperiodic conditions in June (when photoperiod is longest) from natural to short (8L-16D) or long (16L-8D) photoperiod using underyearling male sockeye salmon to clarify the relationship between precocious maturation and the development of the brain-pituitary-gonadal axis. We examined testicular development and measured sGnRH contents in the brain and pituitary, and GTH subunit (GTH I $\beta$ and GTH II $\beta$ ) contents in the pituitary.

\section{Materials and Methods}

Fish

Experiments were conducted at the Nikko Branch of the National Research Institute of Aquaculture, Nikko, Tochigi Prefecture. Sockeye salmon eggs were fertilized artificially in August 1988 and hatched in October 1988. The fish were reared in indoor tanks under natural photoperiod using spring water of constant temperature $\left(9-10^{\circ} \mathrm{C}\right)$ before conducting experiments. Although the fish of both sexes matured at 3 years of age, some males precociously matured at 2 years of age. On June 7, 1989, 500 underyearling sockeye salmon of both sexes (mean body

\footnotetext{
'Present address: School of Fisheries Sciences, Kitasato University, Sanriku, Iwate 022-01, Japan.
} 
weight $8.0 \mathrm{~g}$ ) were randomly selected from a stock and were divided into the following two categories (250 fish each): short photoperiod group (8L-16D; lights on 09:00$17: 00$ ), and long photoperiod group (16L-8D; lights on 04:00-20:00). Each group was transferred to a dark room shielded with black cloth. Photoperiod was manipulated using four 10-W fluorescent lamps (two lamps on each tank) and a timer. The fish were reared in round tanks ( 80 $\mathrm{cm}$ diameter and $300 \mathrm{l}$ volume) using spring water of constant temperature $\left(9-10^{\circ} \mathrm{C}\right)$ throughout the experiment.

\section{Sampling}

We sampled only male fish; data for females were omitted from analysis in this study. Tissues for hormone analyses were collected on June 7, August 8, August 23, September 13 and October 11. Sampling procedures were described by Amano et $a l .^{10)}$ At autopsy, fish were randomly selected and anesthetized in ethyl-p-aminobenzoate $(0.05 \%)$. After measurements of body length (BL) and body weight (BW), brain (olfactory bulb, telencephalon including preoptic area, hypothalamus) and pituitary intended for the measurement of sGnRH and GTH (GTH I $\beta$ and GTH II $\beta$ ) were removed and frozen on dry ice. The brain and pituitary tissues were stored at $-80^{\circ} \mathrm{C}$ until extraction. Gonads were fixed with Bouin's fluid for 24 hours and then their weights were measured for determination of gonadosomatic index (GSI). Gonads were embedded in paraffin and sectioned at $5 \mu \mathrm{m}$. The sections were stained with hematoxylin and eosin for histological observation.

\section{GnRH and GTH RIAs}

$s \mathrm{GnRH}$ contents in the brain and pituitary, and GTH I $\beta$ and GTH II $\beta$ contents in the pituitary were measured by RIA. Methods for the extraction and measurement of GnRH and GTH were as described in Okuzawa et al. ${ }^{11)}$ and Amano et al. ${ }^{10\rangle}$ It was ascertained by HPLC-RIA analysis that sockeye salmon brain contains sGnRH. Brain extracts of sockeye salmon showed displacement curves which were parallel to the curves for the sGnRH standard. Moreover, displacement curves for pituitary samples of sockeye salmon were parallel to the standard curves in both GTH I $\beta$ and GTH II $\beta$ RIA (data not shown).

\section{Statistics}

The Student's $t$-test, Cochran-Cox test, Duncan's new multiple range test and Kruskal-Wallis test were used for statistical analysis.

\section{Results}

\section{Growth}

BL was significantly larger in the $16 \mathrm{~L}-8 \mathrm{D}$ group than in the $8 \mathrm{~L}-16 \mathrm{D}$ group in early and late August (Fig. 1A). BW was significantly larger in the $16 \mathrm{~L}-8 \mathrm{D}$ group than in the $8 \mathrm{~L}-16 \mathrm{D}$ group in late August (Fig. 1B).

\section{Gonadal Development}

Precocious males did not appear throughout the experiment in either photoperiodic group; primary spermatogonia or secondary spermatogonia were observed in all individuals (data not shown). However, GSI showed wider distribution in the $8 \mathrm{~L}-16 \mathrm{D}$ group than in the $16 \mathrm{~L}-8 \mathrm{D}$ group
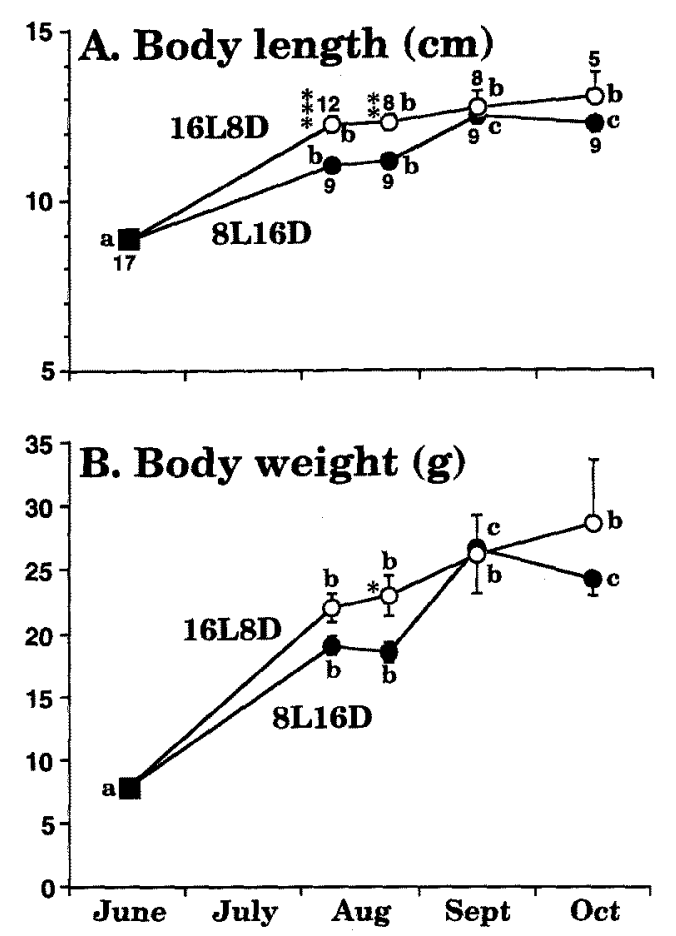

Fig. 1. Changes in body length (A) and body weight (B).

Closed and open circles represent the data of the $8 \mathrm{~L}-16 \mathrm{D}$ and the 16L-8D group, respectively. Numbers beside each symbol indicate the number of fish employed. Each value is expressed as the mean (point) and the standard error (bar). ${ }^{*}(p<0.05),{ }^{* *}(p<0.01)$ and ${ }^{* * *}(p<0.001)$ indicate the levels of significant differences between the $8 \mathrm{~L}-16 \mathrm{D}$ and the $16 \mathrm{~L}-8 \mathrm{D}$ groups. In each group, means with differing letters differ significantly $(p<0.05)$.

in August and September. No remarkable changes in GSI were seen in either the photoperiodic group nor between the $8 \mathrm{~L}-16 \mathrm{D}$ and the $16 \mathrm{~L}-8 \mathrm{D}$ groups throughout the experiment (Fig. 2).

\section{GTH I $\beta$ and GTH II $\beta$ Contents in the Pituitary}

GTH $\mathrm{l} \beta$ contents in the pituitary increased significantly in early August in the $8 \mathrm{~L}-16 \mathrm{D}$ group. GTH I $\beta$ contents in the $8 \mathrm{~L}-16 \mathrm{D}$ group were significantly higher than those in the $16 \mathrm{~L}-8 \mathrm{D}$ group in early and late August and October (Fig. 3). GTH I $\beta$ contents remained at low levels throughout the experiment in the $16 \mathrm{~L}-8 \mathrm{D}$ group. In the $8 \mathrm{~L}-16 \mathrm{D}$ group, GTH I $\beta$ had a highly positive correlation with GSI only in September (correlation coefficient 0.9683 , $p<0.001, \mathrm{n}=9$ ). These positive correlations were not observed in the $16 \mathrm{~L}-8 \mathrm{D}$ group throughout the experiment.

GTH II $\beta$ contents in the pituitary were below the detectable limit ( $1.25 \mathrm{ng} /$ pituitary) in all individuals throughout the experiment (data not shown).

\section{sGnRH Contents in the Brain and Pituitary}

sGnRH contents in the telencephalon tended to be higher in the $8 \mathrm{~L}-16 \mathrm{D}$ group than in the $16 \mathrm{~L}-8 \mathrm{D}$ group from late August, although the differences were not statistically significant (Fig. 4A). sGnRH contents in the hypothalamus also tended to be higher in the $8 \mathrm{~L}-16 \mathrm{D}$ group, and were significantly higher in the $8 \mathrm{~L}-16 \mathrm{D}$ group in September (Fig. 4B). sGnRH contents in the pituitary 


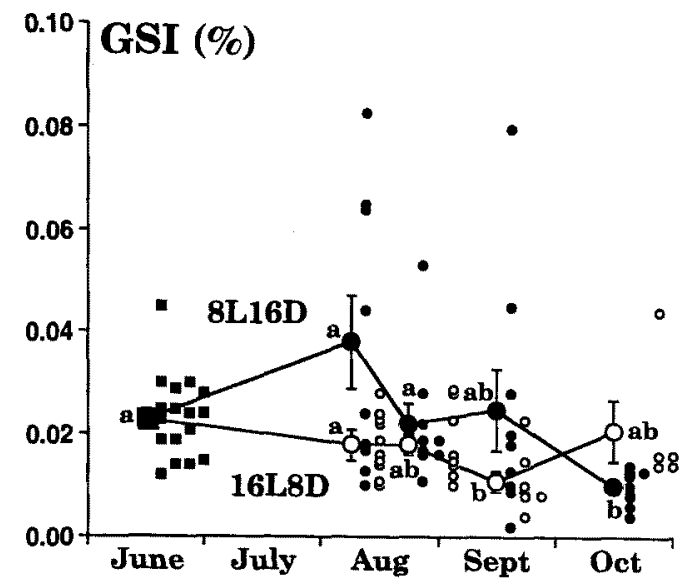

Fig. 2. Changes in gonadosomatic index (GSI).

Data are shown for individual values, the mean and the standard error. Closed and open circles represent the data of the 8L-16D and the $16 \mathrm{~L}-8 \mathrm{D}$ group, respectively. In each group, means with differing letters differ significantly $(p<0.05)$.

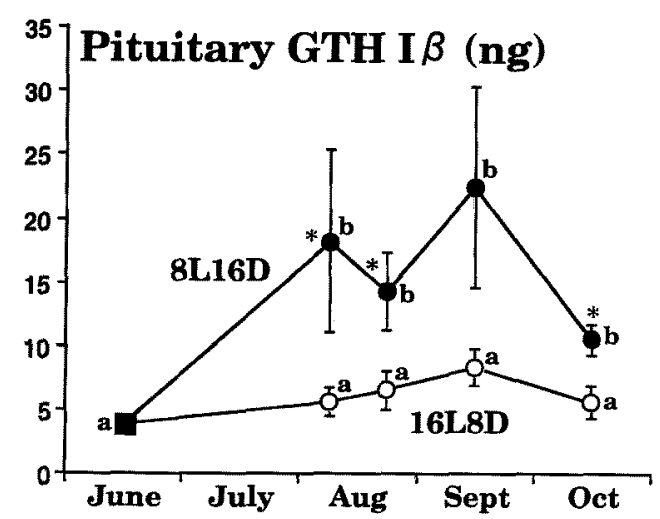

Fig. 3. Changes in pituitary GTH I $\beta$ contents.

Closed and open circles represent the data of the 8L-16D and the 16L-8D group, respectively. Each value is expressed as the mean (point) and the standard error (bar). ${ }^{*}(p<0.05)$ indicates the levels of significant differences between the $8 \mathrm{~L}-16 \mathrm{D}$ and the $16 \mathrm{~L}-8 \mathrm{D}$ groups. In each group, means with differing letters differ significantly $(p<0.05)$.

were below the detectable limit $(4.4 \mathrm{pg})$ in June and early August in all individuals. Levels became detectable and significantly higher in the $8 \mathrm{~L}-16 \mathrm{D}$ group than in the $16 \mathrm{~L}-8 \mathrm{D}$ group in September and October (Fig. 4C). Significant differences in sGnRH contents were not observed in the olfactory bulb between both photoperiodic groups at each sampling time (data not shown).

\section{Discussion}

Short photoperiodic manipulation increased levels of sGnRH (hypothalamus and pituitary) and GTH I $\beta$ (pituitary), although precocious maturation was not induced in the present study. These results suggest that synthesis and storage of $s \mathrm{GnRH}$ increased under short photoperiod and then sGnRH stimulates GTH I $\beta$ synthesis. It is reported that GTH I is involved in the early phases of spermatogene-
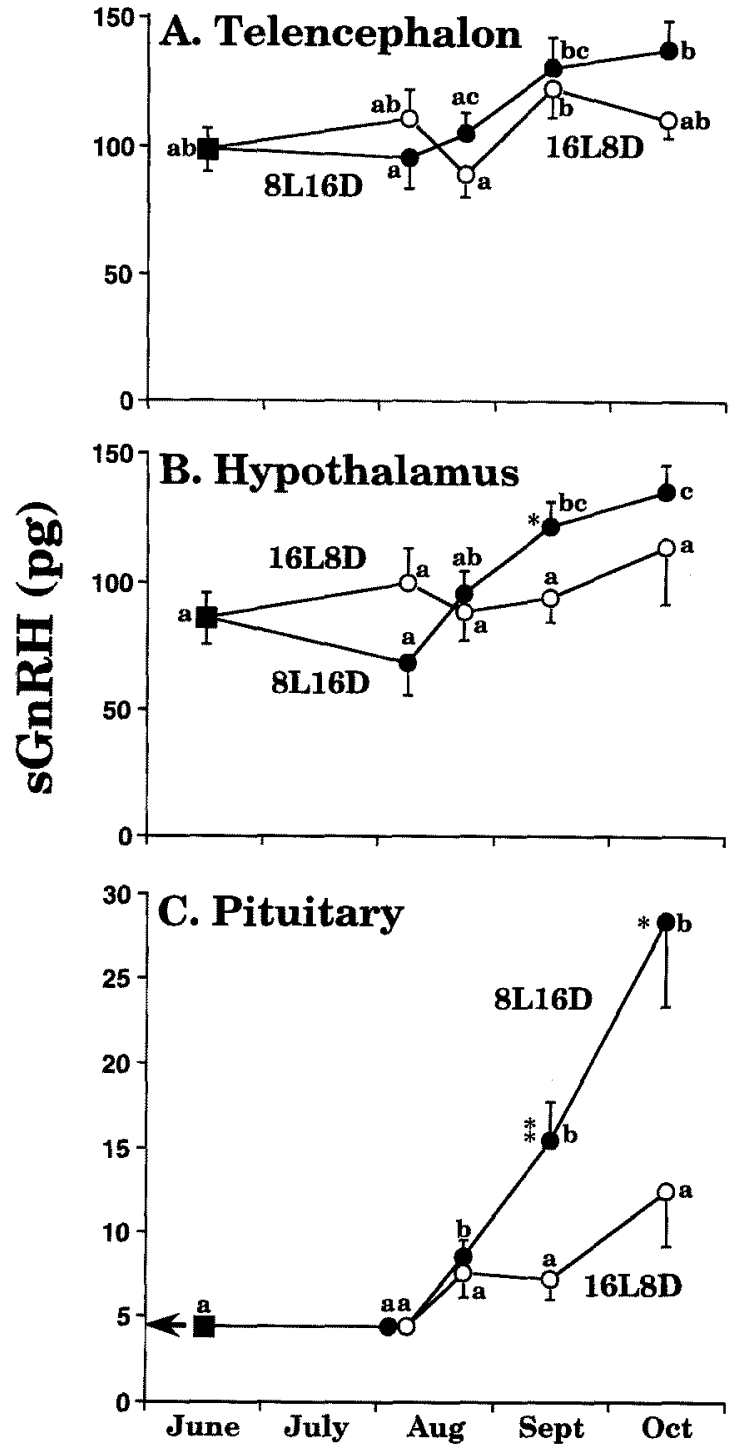

Fig. 4. Changes in sGnRH contents in the telencephalon (A), the hypothalamus (B), and the pituitary (C)

Closed and open circles represent the data of the $8 \mathrm{~L}-16 \mathrm{D}$ and the 16L-8D group, respectively. Each value is expressed as the mean (point) and the standard error $(\mathrm{bar}) .^{*}(p<0.05)$ and ${ }^{* *}(p<0.01)$ indicate the levels of significant differences between the $8 \mathrm{~L}-16 \mathrm{D}$ and the 16L-8D groups. In each group, means with differing letters differ significantly $(p<0.05)$. Arrow indicates the detectable limit.

sis in salmonid fishes. ${ }^{12,13)}$ Indeed, GTH I $\beta$ was positively correlated with GSI in September in the short photoperiod group. However, in contrast to GTH I $\beta$, levels of pituitary GTH II $\beta$ were not increased. This result suggests that synthesis and release of GTH II are required for gonadal maturation.

In underyearling male masu salmon, sGnRH mRNA levels in the brain, sGnRH and GTH (GTH I $\beta$ and GTH II $\beta$ ) levels in the pituitary increased with the advancement of testicular maturation, ${ }^{8,9)}$ suggesting that the brain-pituitary-gonadal axis was already completed. On the other hand, it is probable that the brain-pituitary-gonadal axis was not completed in male sockeye salmon, since increase 
of GTH II levels and induction of testicular maturation were not observed. This species-specific difference in the development of the brain-pituitary-gonadal axis may underlie differences in the initiation of precocious maturation. If we had used yearling male sockeye salmon whose brainpituitary-gonadal axis is considered to be completed, testicular maturation might have been accelerated by manipulating photoperiod.

There are some evidences suggesting retarded development of the sGnRH system in sockeye salmon compared to masu salmon. In underyearling male fish in June, sGnRH contents were lower in sockeye salmon than masu salmon. In sockeye salmon (mean BL: $8.8 \mathrm{~cm}, \mathrm{BW}: 7.9 \mathrm{~g}$ ), sGnRH contents in the telencephalon and the hypothalamus were $98 \mathrm{pg}$ and $86 \mathrm{pg}$ and sGnRH was below the detectable limits $(4.4 \mathrm{pg})$ in the pituitary, whereas in masu salmon (mean BL: $8.0 \mathrm{~cm}, \mathrm{BW}: 7.4 \mathrm{~g}$ ), sGnRH contents in the telencephalon, the hypothalamus and the pituitary were $265 \mathrm{pg}, 312 \mathrm{pg}$ and $10 \mathrm{pg}$, respectively. ${ }^{87}$ It is also suggested that the appearance of sGnRH-immunoreactive (ir) cell bodies and fibers as detected by immunocytochemistry is delayed in sockeye salmon compared to masu salmon. In sockeye salmon, sGnRH-ir cell bodies and fibers in the brain were first detected in the fish 10 months after hatching, ${ }^{14)}$ whereas in masu salmon, sGnRH-ir fibers were already detected in fish just after hatching and sGnRH-ir cell bodies were first detected in fish 5 months after fertilization. ${ }^{15)}$

BL was significantly larger in the long photoperiod group than in the short photoperiod group, suggesting that long photoperiod stimulates growth hormone $(\mathrm{GH})$ secretion. This hypothesis is supported by the results in underyearling masu salmon that plasma GH levels increased after changing the photoperiod from short (8L-16D) to long (13L-11D). ${ }^{16)}$ Incidentally, sGnRH is known to stimulate not only GTH release but also $\mathrm{GH}$ release from the pituitary in goldfish Carassius auratus ${ }^{17,18)}$ and sockeye salmon (Amano et al., unpublished data). In masu salmon, the differentiation of precocious males may occur in May, when the photoperiod is long. ${ }^{19)}$ Taken together, it is possible that $\mathrm{GH}$ secreted under a long photoperiod has some role in initiating precocious maturation. This hypothesis is supported by the observations that body growth plays an important role in the differentiation of precocious and immature males in masu salmon; precocious males are larger in BL than immature males. ${ }^{4,5)}$

In summary, it is suggested that, in contrast to masu salmon, the brain-pituitary-gonadal axis is not completed in underyearling male sockeye salmon. This speciesspecific difference in the development of the brain-pituitary-gonadal axis may underlie differences in the period of precocious maturation.

Acknowledgments We thank Mr. Toshio Shikama and $\mathrm{Mr}$. Saburo Oda, Nikko Branch of the National Research Institute of Aquaculture, for their technical assistance. We also thank Dr. Marcy N. Wilder, Japan International Research Center for Agricultural Sciences, for reviewing the manuscript.

\section{References}

1) L. W. Crim and D. M. Evans: Seasonal levels of pituitary and plasma gonadotropin in male and female Atlantic salmon parr. Can. $J$.
Zool., 56, 1550-1555 (1978)

2) P. A. C. Stuart-Kregor, J. P. Sumpter, and J. M. Dodd: The involvement of gonadotrophin and sex steroids in the control of reproduction in the parr and adults of Atlantic salmon, Salmo salar L. J. Fish Biol., 18, 59-72 (1981).

3) H. Ueda, Y. Nagahama, F. Tashiro, and L. W. Crim: Some endocrine aspects of precocious sexual maturation in the amago salmon Oncorhynchus rhodurus. Nippon Suisan Gakkaishi, 49, 587-596 (1983).

4) H. Utoh: Study of the mechanism of differentiation between the stream resident form and the seaward migratory form in masu salmon, Oncorhynchus masou Brevoort. I. Growth and sexual maturity of precocious masu salmon parr. Bull. Fac. Fish. Hokkaido Univ., 26, 321-326 (1976).

5) H. Utoh: Study of the mechanism of differentiation between the stream resident form and the seaward migratory form in masu salmon, Oncorhynchus masou Brevoort. II. Growth and sexual maturity of precocious masu salmon parr (2). Bull. Fac. Fish. Hokkaido Univ., 28, 66-73 (1977).

6) K. Ikuta: Endocrinological studies on smoltification of masu salmon, Oncorhynchus masou. Ph.D. thesis, The University of Tokyo, Tokyo, 1988, p. 95.

7) J. M. Redding, and R. Patino: Reproductive Physiology, in "The Physiology of Fishes" (ed. by D. H. Evans), CRC Press. Florida, 1993, pp. 503-534.

8) M. Amano, N. Okumoto, S. Kitamura, K. Ikuta, Y. Suzuki, and K. Aida: Salmon gonadotropin-releasing hormone and gonadotropin are involved in precocious maturation induced by photoperiod manipulation in underyearling male masu salmon, Oncorhynchus masou. Gen. Comp. Endocrinol., 95, 368-373 (1994),

9) M. Amano, S. Hyodo, S. Kitamura, K. Ikuta, Y. Suzuki, A Urano, and $K$. Aida: Short photoperiod accelerates preoptic and ventral telencephalic salmon GnRH synthesis and precocious maturation in underyearling male masu salmon. Gen. Comp. Endocrinol., 99, 22-27 (1995).

10) M. Amano, K. Aida, N. Okumoto, and Y. Hasegawa: Changes in salmon GnRH and chicken GnRH-II contents in the brain and pituitary, and GTH contents in the pituitary in female masu salmon, Oncorhynchus masou, from hatching through ovulation. Zool. Sci, 9 , 375-386 (1992).

11) K. Okuzawa, M. Amano, M. Kobayashi, K. Aida, I. Hanyu, Y. Hasegawa, and K. Miyamoto: Differences in salmon GnRH and chicken GnRH-II contents in discrete brain areas of male and female rainbow trout according to age and stage of maturity. Gen. Comp. Endocrinol., 80, 116-126 (1990).

12) H. Kawauchi, K. Suzuki, H. Itoh, P. Swanson, N. Naito, Y. Nagahama, M. Nozaki, Y. Nakai and S. Itoh: The duality of teleost gonadotropins. Fish Physiol. Biochem., 7, 29-38 (1989).

13) P. Swanson, M. Bernard, M. Nozaki, K. Suzuki, H. Kawauchi, and W. W. Dickhoff: Gonadotropins I and II in juvenile coho salmon. Fish Physiol. Biochem., 7, 169-176 (1989).

14) I. S. Parhar, M. Iwata, D. W. Pfaff, and M. Schwanzel-Fukuda: Embryonic development of gonadotropin-releasing hormone neurons in the sockeye salmon. J. Comp. Neurol., 362, 256-270 (1995).

15) M. Amano: GnRH profiles during the life cycle of salmonid fishes. Ph.D, thesis, The University of Tokyo, Tokyo, 1993, p. 45.

16) N. Okumoto, K. Ikuta, K. Aida, I. Hanyu, and T. Hirano: Effects of photoperiod on smoltification and hormonal secretion in masu salmon, Oncorhynchus masou. Aquaculture., 82, 63-76 (1989).

17) T. A. Marchant, and R. E. Peter: Hypothalamic peptides influencing growth hormone secretion in the goldfish, Carassius auratus. Fish Physiol. Biochem., 7, 133-139 (1989).

18) T. A. Marchant, J. P. Chang, C. S. Nahorniak, and R. E. Peter: Evidence that gonadotropin-releasing hormone also functions as a growth hormone-releasing factor in the goldfish. Endocrinology, 124, 2509-2518 (1989).

19) M. Amano, K. Aida, N. Okumoto, and Y. Hasegawa: Changes in levels of GnRH in the brain and pituitary and GTH in the pituitary in male masu salmon, Oncorhynchus masou, from hatching to maturation. Fish Physiol. Biochem., 11, 233-240 (1993), 